\title{
THE TRIPLE TREATMENT OF TUBERCULOID LEPROSY
}

\author{
A. R. DAvisOn, M.R.C.S., ENG., L.R.C.P., LONIOON \\ Westfort Institution, Pretoria
}

A tuberculoid case is considered to be active as long as elevation persists in the maculae or if erythema remains in the lesions or if the lesions continue to spread. When none of these three conditions is present and only a flat hypopigmented blemish remains we consider the case to be clinically cured provided the skin and nasal smears are negative.

In 1948 I reported' on the effect of antimony as an adjuvant treatment to chaulmoogra injections. This expedited the arrest of the disease in certain types of the disease and in some instances the results were dramatic but the average period before arrest was achieved in tuberculoid cases was two years. In 1954 I reported $^{2}$ on the effect of Atebrin on various manefestations of leprosy. This followed on the work of Page ${ }^{3}$, Woodburne et al ${ }^{4}$ and Rogers and Finn ${ }^{5}$ who were reporting on the effects of antimalarial treatment on Lupus Erythematosis. We found Atebrin to be of use in lepromatous cases in that it expedited the resolution of nodules and lepromatous plaques and macules but as it had no effect on the bacillary index we do not use it now on our lepromatous cases. In our borderline cases we find it causes resolution of lesions and as the sulphones cause the toal elimination of bacilli in an average of two years we consider Atebrin to be of value to them. In tuberculoid cases its effects are most dramatic. Such cases are usually negative and Atebrin greatly expedites the resolution of the lesions.

The sulphones per se cause arrest of the tuberculoid process but from our experience and from what I can gather from the literature it takes about two years to bring about a clinical cure.

As we were obtaining results with each of the three drugs used separately we decided in 1957 to use all three drugs together.

Posology. DDS is our routine sulphone given in daily doses not exceeding $200 \mathrm{mgm}$. per day. We consider it essential that the induction must be slow so start with $300 \mathrm{mgm}$. per week for the first month. In the second month it is increased to $100 \mathrm{mgm}$. per day and the maximum dose is started in the third month.

Trivalent antimony in the proprietary forms of Fouadin, Anthiomalin or Stibophen is given intramuscularly in a course which totals $50 \mathrm{cc}$. We usually start with $2.5 \mathrm{cc}$. on the first day, then $3.5 \mathrm{cc}$. on the second day and then $5 \mathrm{cc}$. daily except Sunday. Some patients are intolerant of this dosage and suffer from nausea and vomiting. We then reduce the dosage to $3 \mathrm{cc}$. daily or if this is not acceptable we give $3 \mathrm{cc}$. on alternate days. After $50 \mathrm{cc}$. has been 
given we stop the antimony for 30 days and then resume at the low dosage.

As an antimalarial we have had most experience with Atebrin which we give once a day in a $200 \mathrm{mgm}$. dose for 6 days per week for three weeks. This is followed by a weeks rest. The signs of toxicity to be looked for are headache, abdominal pain or Atebrin psychosis. All these complications we have found to be extremely rare.

Atebrin at first causes hyperpigmentation in some cases. This is particularly common in spongy succulent tuberculoid maculae. This hyperpigmented skin may be restored to natural colour by painting with a 1 in 1 watery solution of trichloracetic acid. After painting the lesion we neutralise the acid with a solution of bicarbonate of soda.

We studied the type of lesions encountered in 20 females and 20 males admitted between the period May, 1957 to October, 1957. The results show that 2 females and one male still show signs of activity after 13,10 and 11 months respectively. The other 37 patients have become clinically cured in an average of 5 months.

Relapses are extremely infrequent but as a precautionary measure we continue a maintenance dose (100 mgm. daily) of sulphone for a minimum period of two years after a clinical cure has been obtained.

\section{Summary}

1. Clinical activity of tuberculoid maculae is confirmed by the presence of erythema, elevation, or the spread of lesions.

2. It is recommended that tuberculoid leprosy should be treated by the simultaneous administration of sulphones, trivalent antimony and Atebrin. The administration of the sulphone should be continuous but trivalent antimony is given in courses of $50 \mathrm{ccs}$. separated by a month's rest period. Atebrin is given for three weeks in each month in daily $200 \mathrm{mgm}$. doses.

3. Forty cases are detailed of whom three have not yet responded to treatment. The other 37 required treatment for an average of only five months.

4. It is recommended that sulphones be continued for a minimum period of two years after clinical cure is obtained.

\section{References}

1. Davison, A. R. Antimony in the Treatment of Leprosy. Internat. J. Lep. 16, (1948) No. 1 (23-28).

2. Davison, A. R. Proceedings of a conference on Leprosy held at Westfort, 1954, (P. 41-43).

3. Page, F. Treatment of Lupus Erythematosis with Mepacrine. Lancet 2: $755-758$ (Oct. 27) 1951.

4. Woodburne, A. R., Philpott, O. S. and Philpott, J. A. Quinacrine in the treatment of Solar Dermatoses. A.M.A. Arch. Dermal \& Syph. 70:116 (July) 1954.

5. Rogiers, John and Penn, Owen, A. Ibid (61). 